\title{
Transient and persistent efficiency: An application to Portuguese wineries
}

\author{
Samuel Faria* • Sofia Gouveia • João Rebelo \\ Department of Economics, Sociology and Management (DESG), Centre for Transdisciplinary \\ Development Studies (CETRAD), University of Trás-os-Montes and Alto Douro (UTAD)
}

Received: 1 June 2021

Revised: 27 September 2021

Accepted: 13 October2021

\begin{abstract}
The computation of productive efficiency provides key insights for firm managers and policymakers towards improvements in the competitiveness of businesses and industries, namely those that observe firm heterogeneity and high competition, as is the case of wine. Benefiting from Portuguese wineries panel data, this research measures firms' productive efficiency, decomposing it into transient and persistent. Results allow us to conclude that wineries can boost overall performance through better input management and long-term policies, such as improvements in market regulation and public firm support.
\end{abstract}

Keywords: Wine; Panel data; Productive efficiency; Stochastic frontier models JEL Classification Codes: C23, D22, L22

\section{Introduction}

To survive and to be competitive in international open markets, firms must adopt strategies that lead to the introduction of technology and innovation advances throughout the whole value chain, as well as to be efficient in the use of inputs, which calls for the computation of productive efficiency, the framework of this research letter.

The assessment of firms' productive efficiency has been evolving over the last decades, namely with the development of stochastic frontier analysis (SFA), which allows the decomposition of deviations from the ideal production frontier into the traditional error term (uncontrollable factors) and an inefficiency term (mismanagement). In the SFA approach, defining the rationale for the specification of inefficiency is key to an accurate interpretation of the results (Badunenko and Kumbhakar, 2016; Karagiannis, 2014) and an issue that should deserve more empirical research in different industries (Alvarez and Arias, 2014).

Benefiting from the potential of panel data models, in the last decade, the SFA framework evolved into the decomposition of the inefficiency component into transient (short-term) and persistent (long-term) inefficiency (Kumbhakar et al., 2014). The advantage of this approach is

\footnotetext{
* Corresponding author. E-mail: samuelf@utad.pt.
}

Citation: Faria, S., Gouveia, S., and Rebelo, J. (2022) Transient and persistent efficiency: An application to Portuguese wineries, Economics and Business Letters, 11(1), 16-23.

DOI: $10.17811 /$ ebl.11.1.2022.16-23 
that it allows catching firm heterogeneity as well as improving the knowledge on how firms are managing the input-output relationship in the short-run, or how long-run industry-wide policies are affecting firms' skills and productive efficiency.

Accounting for heterogeneity is especially relevant in industries where the technology of production is dependent on location-specific factors, such as agrifood industries, in which climate or soil quality play a decisive role (Pisulewski \& Marzec, 2019). Additionally, the decomposition into transient and persistent efficiency gains relevance when management practices change over time (Tsionas and Kumbhakar, 2012), even as a response to changes in the external environment in which firms do business.

The wine industry seems to offer a benchmarking of a heterogeneous industry open to high international competition. During the last forty years, globalization reshaped the industry. On the supply side appeared New world countries, gaining market share to the traditional wine countries (Ugaglia et al. 2019). On the demand side consumption patterns lead to changes in the structure of the wine market, towards a more complex and competitive environment (Menghini, 2015), typical of a monopolistic market structure. These changes present unseen challenges to traditional wine producers, who must adapt by reinforcing their efficient use of resources. Bravo-Ureta et al. (2020) include a literature review on technical efficiency in the wine industry The decomposition of productive efficiency is limited to few contributions (Bravo-Ureta et al., 2020; Adom \&Adams, 2020), with further theoretical and empirical research being demanded, particularly benefiting from panel datasets covering highly heterogeneous and competitive markets, such as the Portuguese wine industry.

The Portuguese wine industry encompasses most of the features of a traditional wine country and fulfills the typical characteristics of a monopolistic competition market structure, due to the prevalence of small and medium-sized enterprises (SMEs), competition based on collective and individual reputation, and freedom to enter or exit the market (Hogg and Rebelo, 2018; Behmiri et al., 2019), following a valuing input strategy.

The goal of this research letter is to contribute to a better knowledge of productive efficiency in industries characterized by firm heterogeneity, being a support tool in the decision-making process of both entrepreneurs and public policy bodies. Taking the Portuguese wine industry as an example, specifically the aims are: (i) to estimate productive efficiency of Portuguese wineries, decomposing into transient and persistent components; (ii) to generate knowledge towards an efficient improvement path to stakeholders; and (iii) to provide research guidelines within the topic. Transient and persistent inefficiency have been analyzed for the wine sector by Bravo-Ureta et al. (2020). However, they used cross-sectional data, where the panel structure referred to farm-level and plot-level observations". To the best of our knowledge, this is the first time a decomposition into transient and persistent efficiency in the wine industry has been attempted for time-series cross-sectional data, being the results of innovative insights to this industry, as well as to other industries with similar characteristics. The remainder of this letter is as follows: section 2 introduces the methodology; section 3 describes the data; section 4 presents and discusses the results, and section 5 presents the main conclusions and displays future research lines.

\section{Methodology}

The knowledge of the sources of productive inefficiency paved the way for the development of a new generation of SFA models where firm heterogeneity is considered in the specification and the inefficiency term is divided into a persistent (long-run) component, that does not change over time (for instance quality of fixed assets or firm management rigidity within an organization), and a residual (short-run) inefficiency component, that does vary over time (in this case, better use of inputs would reflect in the short-run inefficiency component). Furthermore, Kumbhakar et al. (2014) propose a model that allows for the inclusion of random firm-effects, 
which are defined as unobserved time-invariant inputs that are not part of inefficiency, such as the quality of the public policy. This is especially true in industries characterized by monopolistic competitive structure, such as wine, prevailing heterogeneity of firms operating in the market, as well as the multitude of wine regions that act as horizontal differentiation, are likely to affect firms' efficiency differently. Given the characteristics of the Portuguese wine industry, the approach proposed by Kumbhakar et al. (2014), i.e., the Generalised True Random Effect (GTRE) model seems to be appropriated, which can be specified as:

$$
\begin{aligned}
y_{i t}=\alpha_{0}+ & f\left(x_{i t} \beta\right)+\mu_{i}+v_{i t}-\tau_{i}-u_{i t} \\
& v_{i t} \sim N\left(0, \sigma_{v}^{2}\right) \\
& u_{i} \sim N^{+}\left(0, \sigma_{u}^{2}\right) \\
& \tau_{i} \sim N^{+}\left(0, \sigma_{\tau}^{2}\right)
\end{aligned}
$$

where $y_{i t}$ denotes the total output of firm $i$ in the year $t$. Similarly, the $x_{i t}$ stands for the inputs used in the production process. Moreover, $\mu_{i}$ identifies the random effects, capturing firm heterogeneity, $v_{i t}$ is statistical noise, $\tau_{i}$ and $u_{i t}$ are respectively the long-run (persistent) and short-run (transient) inefficiency terms. Thus, in this model, the point-estimates of transient and persistent inefficiency are given by

$$
\begin{gathered}
E\left(\tau_{i} \mid v_{i t}+u_{i t}\right) \\
E\left(u_{i t} \mid v_{i t}+u_{i t}\right)
\end{gathered}
$$

Therefore, the point-estimates for overall efficiency arise from the multiplication of $\tau_{i}$ and $u_{i t}$ (Kumbhakar et al. 2014). The GTRE model can be implemented by a multi-step procedure, as in Kumbhakar et al. (2014) or through a one-step simulated maximum likelihood approach (Filippini and Greene, 2016), being the first of simpler computation and flexibility. This paper adopted the multi-step approach proposed by Kumbhakar et al. $(2014)^{1}$.

\section{Data}

To fulfill the technological homogeneity assumption underlying the production function, only wineries that produce and sell wine were included in the sample. The data source is the annual accounting reports, provided by Informa Dun \& Broadsheet. After a screening, where data availability was the main criterion for inclusion, a random sample of 304 firms is considered, which accounts for nearly $30 \%$ of the active firms. The period under analysis is from 2014 to 2019 , representing the longest time series for which we have available data.

The total annual value of turnover is considered as output (Kallas \& Lambarra, 2010). As inputs, the traditional factors labor and capital (Canello \& Vidoli, 2020) are included through the number of employees and the value of annual depreciation and amortizations of capital. Additionally, we include the cost of raw materials (CRM), which includes the cost of grapes,

Table 1. Descriptive statistics.

\begin{tabular}{llrrrr}
\hline \hline Variable & Unit & Mean & Std. dev. & Min. & Max. \\
\hline Turnover & Euro & $2,756,579$ & $9,323,800$ & 1096.53 & $121,171,290.66$ \\
Employees & Number & 14.64 & 39.78 & 1 & 638 \\
Depreciations & Euro & $149,658.70$ & $379,871.40$ & 35.79 & $5,209,472$ \\
Cost of raw materials & Euro & $1,495,161$ & $4,714,258$ & 21.71 & $41,618,239.74$ \\
Supplies and services & Euro & 550,666 & $2,534,636$ & 940.77 & $40,125,877.36$ \\
\hline \hline
\end{tabular}

Note: All variables are in constant prices, with 2015 as the base year. The GDP deflator was retrieved from the WDI database from World Bank.

\footnotetext{
${ }^{1}$ All econometric estimations were made in software Stata, following the guidelines for computation of the GTRE model provided by Kumbhakar et al. (2015).
} 
Figure 1. Adaptive Kernel density vs normal density.

(a) LnTurnover

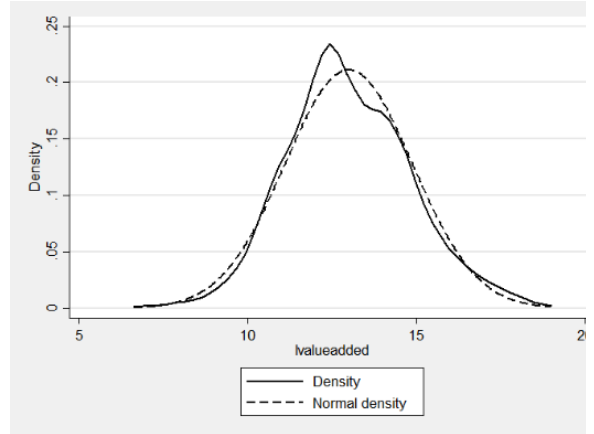

(d) LnCRM

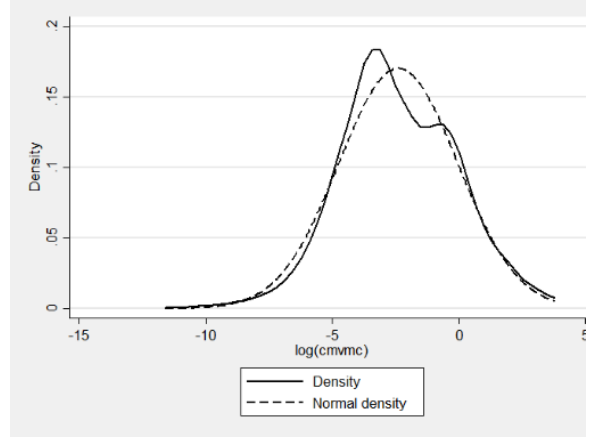

(b) LnEmployees

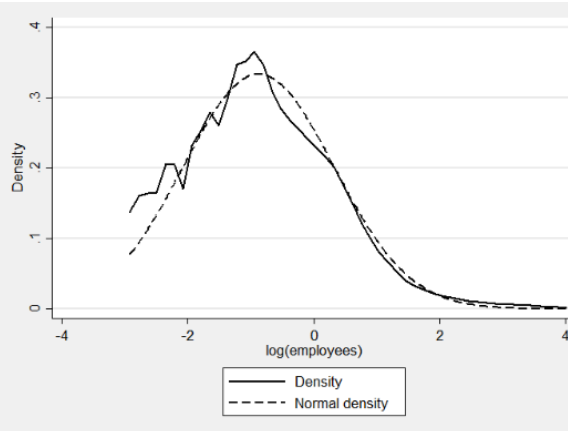

(e) LnSSE

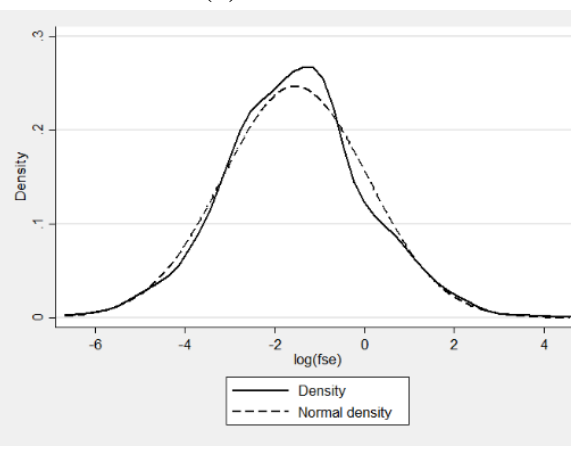

(c) LnDepreciations

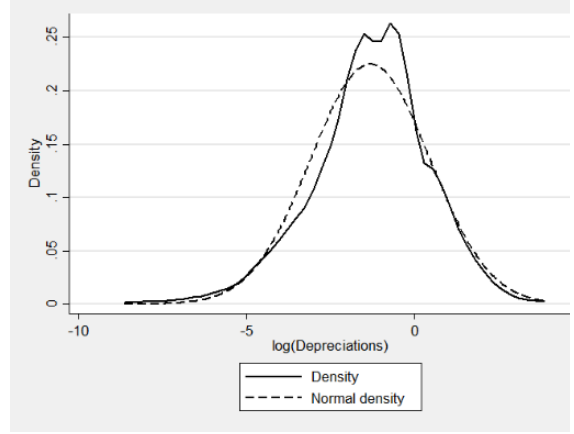

bottles, and other materials included in the production (main input to wine production), and the cost of supplies and services (SSE), which includes goods and services required to firms' operation, such as fuel, electricity, marketing or communication costs (Martínez-Victoria et al., 2019). Table 1 shows the descriptive statistics of the sample and Figure 1 plots the adaptive Kernel and the normal density to the log-values of each variable. Both Table 1 and Figure 1 confirm the heterogeneity of the Portuguese wineries.

\section{Results}

The use of the likelihood ratio (LR) test indicates that the translog production is a better fit for the data than the Cobb-Douglas production function $\left(\mathrm{Chi}^{2}(12)=190.24 * * *\right)$. The Breusch-Pagan LM results $($ Chi2 $(1)=824.87 * * *)$ confirm the presence of panel effects. The LM test for groupwise heteroskedasticity was performed, with the results (Chi2(304) $=0.00004^{* * *}$ ) supporting the presence of heteroskedasticity. Following these, the model was estimated and the results $^{2}$ are presented in Table 2 as well as the averages of the overall, transient, and persistent productive efficiency.

The results point to slightly increasing returns to scale ${ }^{3}$. Specifically, the sum of the first-order coefficients of the translog ${ }^{4}$ suggest that a proportional increase in the inputs provides an increase of $5.67 \%$ in the output. The mean of short-term efficiency is $80.85 \%$, ranging from $18.43 \%$ for the least efficient firm and $96.60 \%$ for the most efficient firm. Similarly, the longrun efficiency presents a mean of $80.42 \%$, with the least efficient firm with $35.53 \%$ and the

\footnotetext{
${ }^{2}$ Since the values of the output and inputs are normalized around the sample geometric mean, it yields that firstorder parameters are essentially partial input-output elasticities.

${ }^{3}$ The hypothesis of constant returns to scale was assessed through a test of linear restrictions, setting the sum of first-order coefficients equal to 1 . The results $\left(\mathrm{Chi}^{2}(1)=10.44^{* * *}\right)$ reject the null hypothesis, reflecting the presence of increasing returns to scale.

${ }^{4}$ In a translog production function, the scale elasticity is given by $\varepsilon(x)=\sum_{j=1}^{n}\left(\alpha_{i}+\sum_{j=1}^{n} \beta_{i j} \ln x_{j}\right)$ as expressed by Ray (1998).
} 
most efficient showing $96.42 \%$. Overall efficiency spans from $8.19 \%$ for the least efficient firm to $90.78 \%$ for the most efficient firm. These discrepancies in efficiency scores also confirm firms' performing heterogeneity within the industry.

Therefore, in average, wineries can improve their overall performance (via efficiency gains) by nearly $35 \%$, through improvements in their short-term management of inputs by $20 \%$, and pursuing long-term strategies to boost sales, such as penetrating external markets or R\&D expenditures for innovation. The long-term performance can be improved by nearly $20 \%$ as well. Figure 2 displays the histogram for both transient and persistent efficiency scores. Short-term efficiency is largely concentrated near the mean, displaying low differences between firms, suggesting firms operate with similar input management strategies and confirming technological homogeneity, despite the diversity in their structure, namely in size. Long-term efficiency is more scattered, suggesting different causes for long-term inefficiency, which calls for the need for the development of differentiated entrepreunerial decisions, such as firm location (wine region), firm size, capital structure, market positioning, integration in the supply chain, and that can be shaped by public policies.

The results suggest that there is room for improvements at both firm-level and country-wide levels. From a managerial point of view, firms should reassess their input management relationship, specifically, developing supplier relationships, generating economies of scale, and en-

Table 2. Econometric results.

\begin{tabular}{|c|c|}
\hline Variable & Coefficient \\
\hline LnEmployees & $0.0157(0.0426)$ \\
\hline LnDepreciations & $0.1104 * * *(0.0373)$ \\
\hline LnCRM & $0.5387 * * *(0.0379)$ \\
\hline LnSSE & $0.3918 * * *(0.0580)$ \\
\hline LnEmployees*LnDepreciations & $0.0203(0.0500)$ \\
\hline LnEmployees*LnSSE & $0.1204(0.1100)$ \\
\hline LnEmployees*LnCRM & $-0.2334 * * *(0.0688)$ \\
\hline LnDepreciations*LnSSE & $-0.0911 * *(0.0375)$ \\
\hline LnDepreciations*LnCRM & $0.0255(0.0330)$ \\
\hline LnSSE*LnCRM & $0.0369(0.0841)$ \\
\hline $\mathrm{T}$ & $0.0177 * * *(0.0073)$ \\
\hline $\mathrm{T}^{*}$ LnEmployees & $0.0146(0.0232)$ \\
\hline $\mathrm{T}^{*}$ LnDepreciations & $0.0183(0.0159)$ \\
\hline T*LnCRM & $0.0192(0.0190)$ \\
\hline T*LnSSE & $-0.0376(0.0298)$ \\
\hline $\mathrm{T}^{2}$ & $-0.0197 * * *(0.0067)$ \\
\hline LnEmployees $^{2}$ & $-0.0041(0.0449)$ \\
\hline LnDepreciations $^{2}$ & $0.0386 * *(0.0191)$ \\
\hline LnCRM $^{2}$ & $0.0577 *(0.0314)$ \\
\hline $\operatorname{LnSSE}^{2}$ & $0.0263(0.0631)$ \\
\hline \multicolumn{2}{|l|}{$\mathrm{N}=1824$} \\
\hline \multicolumn{2}{|l|}{$R^{2}=0.9306$} \\
\hline \multicolumn{2}{|l|}{ Wald: $\chi^{2}(20)=8745.52 * * *$} \\
\hline \multicolumn{2}{|c|}{ Mean of efficiency estimates } \\
\hline \multicolumn{2}{|c|}{ Transient efficiency: 0.8085} \\
\hline \multicolumn{2}{|l|}{ Persistent efficiency: 0.8042} \\
\hline Overall efficiency: 0.6523 & \\
\hline
\end{tabular}

Note: $\mathrm{T}$ denotes a time-trend proxy variable to catch technological change. Robust standard errors are in brackets and $* * *, * *$ and $*$ denote significance at the $1 \%, 5 \%$ and $10 \%$ level, respectively. 
Figure 2. Histogram of efficiency scores.

(a) Transient efficiency

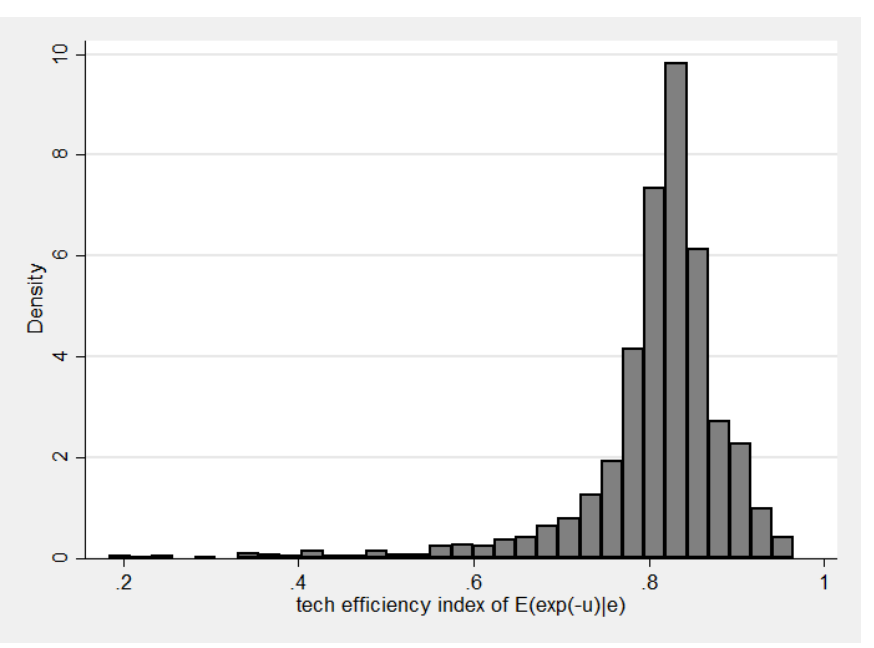

(b) Persistent efficiency

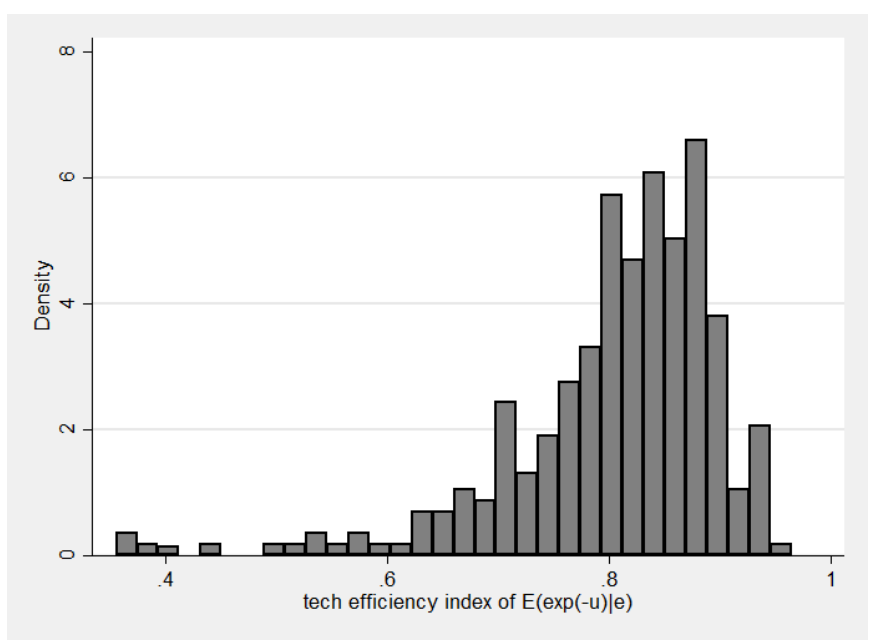

engage in innovation activities, specifically through networks of know-how sharing, to absorb the best practices, as referred by Bravo-Ureta et al, (2020).

Structurally, the results show that there is a need for a long-term strategy of the industry, which calls for the design of policies that allow firms to penetrate new markets (exports) and boost the value of their product in the international competitive scenario, which is in line with the findings of Canello \& Vidoli (2020). These policies should consider the specificities of firms within the industry (due to high heterogeneity) since firms benefit differently from support policies according to their characteristics (Náglova \& Pechrová, 2019), such as the wine region where they are located (Canello \& Vidoli, 2020).

\section{Conclusions and looking forward}

This research confirms the relevanceof decomposing productive efficiency into transient and persistent components, to a better understanding of the structure and conduct of industries open to international markets and characterized by heterogeneous firms, both of size and marketing strategies. Thus, besides deepening the scientific knowledge on the efficiency approach in the wine industry, the results can also be used as a benchmarking for similar agri-food industries.

As referred by O'Donnel (2018), albeit firm managers have a limited capacity or "bounded rationality" to make rational (i.e., optimal) in-time decisions to improve efficiency, the results show that there is room for Portuguese wineries to improve performance both in the short- and long-run, such as adjustments in the internal production chain, appropriate advertising, promotion and communication directed to consumers, a meticulous price/quality positioning, or a branding strategy aligned with the market target. Most of these decisions involve sunk cost traits that typically SMEs try to avoid and might be challenging for managers since most of the firms are familiar SMEs who struggle to get financing from capital markets, which has worsened by the decrease of sales in 2020 and 2021 (accompanied by an increase in operating average costs) due to the COVID-19 pandemic.

The results also show that appropriate business support public policies can improve industry competitiveness, namely through persistent efficiency gains. Specifically, such policies could be directed towards (i) fostering market access, such as promotion and firms' collaborative marketing system in international markets, bilateral and multilateral trade agreements, intelligent market systems providing usable insights and (ii) facilitating the adaptation of the products to the markets, for example, in the case of the EU, through the reduction of diversity of acronyms for wines with designation of origin, in line with the specificities and behavior of different 
markets and consumer segments and/or by allowing the production of wines with low or zero alcohol content. Additionally, policies should be oriented to (iii) favoring the development of innovative clusters, through the incorporation of the results of public research and development into firms' operations, and (iv) towards financial support, so firms' can overcome exogenous shocks, as in the current COVID-19 crisis. In such cases, knowledge about persistent and transient productive efficiency can be a decisive tool to separate zombie firms from feasible ones.

The history of research on productive efficiency shows us that we are in the presence of an unfinished avenue, a statement well supported by developments during the last decade on the stochastic frontier panel data models. However, in these models, there is still a long pathway in fields such as the dynamic nature of inefficiency and the role of endogeneity in the specification (Karakaplan and Kutlu, 2017); the inclusion of spatial econometric models to catch the effect of neighboring and clustering, since in agrifood industries spatial variables are of additional relevance (Bravo-Ureta et al., 2020) and the determinants of both persistent and transient efficiency. The short and long-run impact of COVID-19 on the wineries structure and behavior and consequently on the productive performance is another field that should be researched to reach a better understanding and foresight of a firm’s external shocks.

\section{Acknowledgements}

This study has received support from: the FEDER - Interreg SUDOE project SOE3/P2/F0917, VINCI - Wine, Innovation and International Competitiveness, and the FCT - Portuguese Foundation for Science and Technology, project UIDB/SOC/04011/2020.

\section{References}

Adom, P., \& Adams, S. (2020). Decomposition of technical efficiency in agricultural production in Africa into transient and persistent technical efficiency under heterogeneous technologies. World Development, 129. https://doi.org/10.1016/j.worlddev.2020.104907

Alvarez, A., \& Arias, C. (2014). A selection of relevant issues in applied stochastic frontier analysis. Economics and Business Letters, 3(1), 3-11.

Badunenko, O., \& Kumbhakar, S. (2016). When, where and how to estimate persistent and transient efficiency in stochastic frontier panel data models. European Journal of Applied Research, 255(1), 272-287. http://dx.doi.org/10.1016/j.ejor.2016.04.049

Behmiri, N., Rebelo, J., Gouveia, S., \& António, S. (2019). Firm characteristics and export performance in Portuguese wine firms. International Journal of Wine Business Research, 31(3), 419-440. https://doi.org/10.1108/IJWBR-07-2018-0032

Bravo-Ureta, B., Moreira, V., Troncoso, J., \& Wall, A. (2020). Plot-level efficiency accounting for farm-level effects: Evidence from Chilean wine grape producers. Agricultural Economics, 51(6), 811-824. https://doi.org/10.1111/agec.12593

Canello, J., \& Vidoli, F. (2020). Investigating space-time patterns of regional industrial resilience through a micro-level approach: an application to the Italian wine industry. Journal of Regional Science, 60(4), 1-24. doi: 10.1111/jors. 12480.

Fillippini, M., \& Greene, W. (2016). Persistent and transient productive inefficiency: a maximum likelihood approach. Journal of Productivity Analysis, 45(2), 187-196. https://doi.org/10.1007/s11123-015-0446-y

Hogg, T. \& Rebelo, J. (2018). Rumo Estratégico para os Vinhos do Douro e Porto. Universidade de Trás-os-Montes e Alto Douro (UTAD), ISBN 978-989-704-344-4.

Kallas, Z., \& Lambarra, F. (2010). Technical efficiency and firm exit in the wine and meat sector: policy implications. New Medit, 9(2). 25-31. 
Karagiannis, G. (2014). Modeling issues in applied efficiency: agriculture. Economics and Business Letters, 3(1), 12-18.

Karakaplan, M, \& Kutlu, L. (2017). Handling endogeneity in Stochastic Frontier Analysis, Economics Bulletin, 37(2), 889-901.

Kumbhakar, S. C., Lien, G., \& Hardaker, J. B. (2014). Technical efficiency in competing panel data models: A study of Norwegian grain farming. Journal of Productivity Analysis, 41(2), 321-337. https://doi.org/10.1007/s11123-012-0303-1

Martínez-Victoria, Mc., Maté-Sánchez-Val, M., \& Lansink, A. O. (2019). Spatial dynamic analysis of productivity growth of agri-food companies. Agricultural Economics (United Kingdom), 50(3), 315-327. https://doi.org/10.1111/agec.12486

Menghini, S. (2015). The new market challenges and the strategies of the wine companies. Wine Economics and Policy, 4(2), 75-77. https://doi.org/10.1016/j.wep.2015.11.003

Náglova, Z., \& Pechrová, M. S. (2019). Are wine producers with subsidies more technically efficient? Central European Business Review, 8(1), 1-14. doi: 10.18267/j.cebr.207

O’Donnel, C. J., (2018). Productivity and Efficiency Analysis: An Economic Approach to Measuring and Explaining Managerial Performance. Springer. https://doi.org/10.1007/978-98113-2984-5.

Pisulewski, A., \& Marzec, J. (2019). Heterogeneity, transiente and persistente technical efficiency of Polish crop farms. Spanish Journal of Agricultural Research, 17(1). https://doi.org/10.5424/sjar/2019171-13926

Ray, S. (1998). Measuring scale efficiency from a translog production function. Journal of Productivity Analysis, 11, 183-194.

Tsionas, E., \& Kumbhakar, S., (2012). Firm heterogeneity, persistent and transient technical inefficiency: a generalized true random-effects model. Journal of Applied Econometrics, 29(1), 110-132. https://doi.org/10.1002/jae.2300

Ugaglia, A. A., Cardebat, J-M., \& Corsi, A. (eds.) (2019). The Palgrave Handbook of Wine Industry Economics. Palgrave Macmillan. 